Check for updates

Cite this: RSC Adv., 2019, 9, 24505

\title{
The size of micro-crystalline tyrosine (MCT®) influences its recognition and uptake by THP-1 macrophages in vitro $\dagger$
}

\author{
Emma Shardlow (D) and Christopher Exley (D) *
}

The physicochemical hallmarks of particulate immunopotentiators play a pivotal role with regards to their adjuvanticity in vivo. These properties have not been fully characterised in the case of MCT®, an amino acid-based adjuvant used as an alternative to aluminium salts in subcutaneous allergy immunotherapy (SCIT). This study presents a full characterisation of MCT® and in a preliminary capacity reveals how parameters, specifically particle size, might influence the recognition of MCT® by antigen presenting cells (APCs) in vitro. Light microscopic analysis demonstrated that MCT® was composed of highly crystalline needles, the majority of which exceeded $10 \mu \mathrm{m}$ in length under physiological conditions (median size $-20.8 \mu \mathrm{m}$ ). While the substantial length of crystals presented a significant barrier to cellular recognition and uptake, isolated incidences of perpendicular recognition were observed owing to the smaller comparative width of crystallites (median size $-2.8 \mu \mathrm{m}$ ). This appeared to allow a small proportion of material to be ingested both fully and partially by THP-1 macrophages, although further studies are required to unequivocally confirm this observation. Preferential recognition of needle tips also favoured the direct presentation of antigen to immune cells as proteinaceous adsorption appeared to be isolated to these regions. Furthermore, the data herein provide valuable insights into the mechanisms surrounding how this adjuvant potentiates an immunological response following administration.

Received 21st May 2019

Accepted 26th July 2019

DOI: $10.1039 / c 9 r a 03831 k$

rsc.li/rsc-advances expected to be antigenic in their own right, their modulatory and stimulatory influence upon immunological events following antigenic challenge is well documented. ${ }^{10,11}$ Aluminium salts represent the quintessential choice of adjuvant for inclusion within SCIT vaccines ${ }^{12}$ and are present in $c a$. $75 \%$ of all formulations intended for this purpose. ${ }^{13}$ Their economic fabrication ${ }^{14}$ and perceived safety ${ }^{15}$ have contributed to their sustained popularity; however, the increasing incidence of aluminium-associated adverse reactions observed in individuals receiving SCIT casts some doubt upon the latter assertion. ${ }^{16-20}$ In fact, the development of localised complications during the course of SCIT administration, which included pruritic nodules,${ }^{21}$ urticaria, ${ }^{22}$ and granulomas ${ }^{19}$ contributed to an increase in patient non-compliance and premature termination of the treatment protocol ( $c a .21 \%$ cases). ${ }^{23}$ Aluminium adjuvants are also particularly inept at inducing cell-mediated responses in murine models instead skewing immunological profiles towards a predominantly Th2 response..$^{24-26}$ Furthermore, the enhanced humoral responses potentiated by aluminium salts in vivo, as characterised by heightened levels of serum IL-4 and IL-13 ${ }^{27}$ appears to be counter-intuitive with regards to the mediation of allergic immunopathology. In conjunction, these factors emphasise the requirement for the development of safer more efficacious alternatives.
The Birchall Centre, Lennard-Jones Laboratories, Keele University, Keele, Staffordshire, ST5 5BG, UK. E-mail: c.exley@keele.ac.uk

$\dagger$ Electronic supplementary information (ESI) available. See DOI: 10.1039/c9ra03831k 
One such promising candidate is the amino acid L-tyrosine (L-tyr), a proprietary formulation manufactured under the registered trademark micro-crystalline tyrosine (MCT®). The immunotherapeutic potential of MCT®-allergen adsorbates in the treatment of allergic rhinitis, for example, has been recently demonstrated in clinical trials using the Pollinex® Quattro short-course administration protocol. ${ }^{28,29}$ The efficacy of MCT ${ }^{\circledR}$ as an adjuvant within prophylactic vaccines against influenza ${ }^{30}$ and malaria ${ }^{31}$ has also been investigated. $\mathrm{L}$-tyr is already present within the human subcutaneous interstitial milieu at a concentration of $c a .54 \mu \mathrm{M}\left(10 \mu \mathrm{g} \mathrm{mL}^{-1}\right)^{32}$ and as such appears to be reasonably well tolerated both systemically and locally at doses $<40 \mathrm{mg} \mathrm{mL}{ }^{-1}$. $^{33,34}$ The diminutive solubility of L-tyr in aqueous media at physiological $\mathrm{pH}\left(c a .0 .45 \mathrm{mg} \mathrm{mL}^{-1}\right)$ also facilitates a controlled and prolonged release of antigenic material at the site of injection, whilst limiting the biopersistence of the adjuvant itself. ${ }^{33,35}$ The transient nature of $\mathrm{L}^{-}$ tyr in the interstitial space is recognised as an important factor governing the safety of this material, minimising the risk of delayed hypersensitivity reactions, granuloma and nodule formation..$^{35}$

How particulate adjuvants facilitate the polarisation and potentiation of the immune response during vaccination is yet to be fully elucidated; however, postulated mechanisms include the induction of pro-inflammatory cytokine secretion through activation of the NALP-3 inflammasome, ${ }^{36-39}$ depot formation ${ }^{35,40,41}$ and improved antigenic cross-presentation through enhanced recognition and uptake by antigen presenting cells (APCs). ${ }^{42-46}$ Recent literature has highlighted the importance of particulate physicochemistry with regards to the subsequent biological activity of adjuvants administered as colloidal suspensions (see review ${ }^{47}$ ). Properties which significantly influence the adjuvanticity of such materials include solid-state structure, particle size, particle shape and zeta potential. ${ }^{14,47}$ The hydrodynamic particle size of adjuvants is particularly important with regards to the recognition of such material by immunocompetent cells at the site of injection, a precursor to particulate uptake and cellular translocation to the draining lymph nodes. ${ }^{47}$ In order to increase the understanding of the mechanisms by which MCT ${ }^{\circledR}$ promotes desensitisation in SCIT, this is the first study to fully characterise the physicochemical properties of MCT ${ }^{\circledR}$ and examine their influence, especially that of particle size, upon the cellular recognition of this adjuvant in vitro.

\section{Materials and methods}

\section{Adjuvants and chemicals}

MCT® stock solutions containing $c a .40 \mathrm{mg} \mathrm{mL}^{-1}$ L-tyr in buffered saline $(0.5 \% \mathrm{w} / \mathrm{v}$ phenol $)$ were provided by Allergy Therapeutics (Worthing, UK) and stored at $4{ }^{\circ} \mathrm{C}$ upon receipt. $\mathrm{L}^{-}$ tyr standard ( $\geq 98 \%$ ) and ovalbumin lyophilate (OVA) ( $\geq 98 \%$ ) were both purchased from Sigma-Aldrich, UK.

\section{Structural characterisation of MCT ${ }^{\circledR}$}

In preparation for structural characterisation, the aqueous phase of $\mathrm{MCT}^{\circledR}$ was removed via filtration through a polycarbonate filter membrane (pore size-50 $\mathrm{nm}$, Poretics Corp., US) using a reduced-pressure filtration system (Millipore, UK). The solid material collected on the membrane was removed and dried in an incubator at $37^{\circ} \mathrm{C}$ for 72 hours. After this duration samples were ground to a fine powder and stored in a calcium chloride desiccator under vacuum until required.

FT-IR spectra were collected between $4000 \& 600 \mathrm{~cm}^{-1}$ using a Thermo Nicolet FT-IR spectrometer with an ATR germanium crystal attachment. Atmospheric background scans were performed in the absence of sample within the experimental range before each measurement and subtracted from subsequent data sets. For each experimental sample, 64 scans were collected in order to enhance the signal to noise ratio and thus spectral quality. Peak assignments and ATR correction algorithms were applied to raw spectra using OMNIC software prior to presentation.

XRD patterns were obtained between $2 \theta$ values of $10^{\circ}$ and $50^{\circ}$ at an interval of $0.5^{\circ}$ using a Bruker D8 Advance powder X-ray diffractometer $(\mathrm{CuK} \alpha$ radiation $-0.154 \mathrm{~nm})$.

TGA analysis was performed over a temperature range of $20-$ $800^{\circ} \mathrm{C}$ (ramp $10^{\circ} \mathrm{C}$ per minute) using a STA 1500 TGA/DSC heatflux simultaneous thermal analyser.

TEM was performed using a JEOL1230 transmission electron microscope (operating voltage - $100 \mathrm{kV}$ ) with a SIS Megaview III digital camera attachment. Samples were prepared upon formvar/carbon coated 200 mesh copper grids (Agar Scientific, UK) according to a procedure adapted from Mold et al. ${ }^{48}$ Briefly, grids were immersed in sample beads $(30 \mu \mathrm{L})$ containing $2 \mathrm{mg}$ $\mathrm{mL}^{-1}$ MCT ${ }^{\circledR}$ in UPW for 2 minutes, wicked to remove excess sample and allowed to dry for $24 \mathrm{~h}$ prior to visualisation. Grids stained using $2 \%$ uranyl acetate $(70 \% \mathrm{v} / \mathrm{v}$ EtOH) were subjected to an additional immersion (30 s), wicking and rinse stage prior to dehydration.

\section{Preparation of vaccines}

A stock solution of L-tyr $\left(c a .40 \mathrm{mg} \mathrm{mL}^{-1}\right)$ was prepared through the addition of physiological saline $(0.9 \% \mathrm{NaCl}$ in UPW, $\mathrm{pH} 7 \pm$ $0.1)$ to L-tyr powder $(0.8 \mathrm{~g})$ and stored at $4{ }^{\circ} \mathrm{C}$ until required.

Model vaccines were prepared via the addition of RT equilibrated stock MCT ${ }^{\circledR}$ or L-tyr dropwise to physiological saline. Where a model antigen was included in the preparation, MCT® or $\mathrm{L}$-tyr was added to physiological saline containing $70 \mu \mathrm{g} \mathrm{mL} \mathrm{mL}^{-1}$ OVA ( $1: 10$ protein to adjuvant ratio). Formulations were adjusted to $\mathrm{pH} 7 \pm 0.1$ using sodium hydroxide $(0.1 \mathrm{M})$ and exposed to constant agitation (ca. $500 \mathrm{rpm}$ ) at RT for $1 \mathrm{~h}$ before analysis or inclusion within subsequent experimental procedures.

\section{Particle size determination}

Size-exclusion filtration. In preparation for the determination of particle size via tyrosine quantification, model vaccines containing $\mathrm{MCT}{ }^{\circledR}$ or $\mathrm{L}$-tyr were subject to syringe filtration using $47 \mathrm{~mm}$ hydrophilic PVDF and PES membranes with nominal pore sizes of $5 \& 0.1 \mu \mathrm{m}$ respectively (Merck Millipore, UK). To increase the accuracy of the data collected, equal volumes of whole vaccine samples were passed through each filter ( $c a .3$ $\mathrm{mL}$ ) and collected for analysis. 
Fluorescence quantification of tyrosine. Tyrosine quantification was performed using a PerkinElmer LS-55 fluorescence spectrometer at an excitation wavelength of $273 \mathrm{~nm}$. Calibration curves were performed prior to each set of measurements using a series of $\mathrm{L}_{\text {-tyr }}$ standard solutions ranging from $0.625-40 \mu \mathrm{M}$, which were prepared through serial dilution of an L-tyr stock solution ( $200 \mu \mathrm{M}$ in UPW) in the relevant experimental diluent. Emission spectra were collected between 250 \& $700 \mathrm{~nm}$ and the concentration of tyrosine in samples was derived from readings taken at ca. $307 \mathrm{~nm}$ ( $\lambda$ max). Experimental values were derived from the averages of three individual measurements made per sample replicate where the RSD of these values $\leq 10 \%$.

Prior to commencing the analysis of vaccine filtrates containing protein, OVA only controls (70 $\mu \mathrm{g} \mathrm{mL} \mathrm{mL}^{-1}$ OVA in saline) were performed in order to negate any fluorescence signal originating from the antigen.

Light microscopy. Measurements of individual particles within MCT®-adjuvanted vaccines were made using an Olympus BX50 fluorescence microscope. Light images were taken at a magnification of $200 \times$ and particle measurements were performed within the Cell D software. Prior to visualisation, MCT® + OVA samples were stained with Congo red solution ( $5 \mathrm{mg} \mathrm{mL}^{-1}$ in $50 \% \mathrm{v} / \mathrm{v} \mathrm{EtOH}$ ) in order to highlight the antigenic material present within the sample.

Zeta potential measurements. The zeta potential of individual samples at RT was measured via electrophoretic light scattering (ELS) using a Malvern Zetasizer Nano ZS. Samples were housed within polystyrene folded capillary cells equipped with gold plated beryllium/copper electrodes for the duration of the measurement. A total of five measurements were made per sample replicate.

Solubility in model interstitial fluid (MIF). The MIF buffers used in solubility experiments incorporate a combination of biologically relevant constituents (Table S1 $\dagger$ ) adapted from studies attempting to elucidate the composition of human interstitial fluid. ${ }^{32,49,50}$ Following preparation, each MIF formulation was adjusted to $\mathrm{pH} 7.4 \pm 0.05$ using sodium hydroxide and stored at $4{ }^{\circ} \mathrm{C}$ prior to use.

MIF $(0.4 \mathrm{~mL})$ was aliquoted into Eppendorf tubes and allowed to reach a temperature of $37^{\circ} \mathrm{C}$ before the addition of vaccines $(0.6 \mathrm{~mL})$ which contained $c a .10 \mathrm{mg} \mathrm{mL}^{-1}$ MCT® or an equivalent phenol only control. Samples were held under constant agitation ( $c a .500 \mathrm{rpm}$ ) for the duration of the experiment and kept at $37^{\circ} \mathrm{C}$ using a water bath.

Supernatants were collected at $T=1,2,3,4,24,48,72$ \& $168 \mathrm{~h}$ and analysed for soluble tyrosine content by fluorescence spectroscopy. Supernatants were obtained through centrifugation of the whole sample at $15000 \mathrm{~g}$ for 5 minutes. A total of $0.5 \mathrm{~mL}$ of the supernatant was carefully aspirated for analysis and the volume removed was replaced with fresh $\operatorname{MIF}\left(37^{\circ} \mathrm{C}\right)$ at each analytical time point.

\section{Cellular experiments}

Maintenance of THP-1 parent cultures. THP-1 cells (ECACC 88081201), originally derived from a one-year old male with acute monocytic leukemia, were obtained from Public Health
England (PHE), UK as a growing culture. Cultures were maintained using RPMI 1640 medium (GlutaMAX ${ }^{\mathrm{TM}}$, Thermo Fisher Scientific, UK) supplemented with HEPES (25 mM), gentamicin $\left(100 \mu \mathrm{g} \mathrm{mL}^{-1}\right)$ and heat inactivated FBS (10\% v/v, US certified). This medium will hereafter be referred to as R10 medium. Parent cultures were maintained at $37{ }^{\circ} \mathrm{C}$ within an atmosphere containing $5 \% \mathrm{CO}_{2}$ and additional humidity. Cell passage was performed when cultures reached a density of $c a \cdot 10^{6}$ cells per $\mathrm{mL}$.

Differentiation of THP-1 cells. Prior to performing the differentiation protocol, the viability of THP-1 cells was confirmed using the trypan blue exclusion test. The procedure used herein was adapted from that optimised by Lund et al. ${ }^{\mathbf{5 1}}$ Briefly, THP- 1 cells were seeded into 24 or 96 well plates at a density of 40000 cells per well and stimulated with $25 \mathrm{nM}$ PMA in R10 medium for a duration of $48 \mathrm{~h}$. Cells in 24 well plates were cultured onto $13 \mathrm{~mm}$ round coverslips which had been sterilised in 70\% v/v EtOH before use. The PMA was then removed from the wells and the cells were allowed to rest for a further $24 \mathrm{~h}$ in fresh R10 medium before treatment. Successful differentiation of THP-1 cells was confirmed using light microscopy (Fig. 10A).

Cellular uptake of MCT. Cells were treated in 24 well plates with vaccines containing $2 \mathrm{mg} \mathrm{mL}^{-1} \mathrm{MCT} 囚$ and left to incubate for $1 \mathrm{~h}$ at $37^{\circ} \mathrm{C}\left(5 \% \mathrm{CO}_{2}\right)$. Cells were then washed twice with PBS $(1 \times)$ and fixed using paraformaldehyde $(0.22 \mu \mathrm{m}$ filtered, $4 \% \mathrm{w} /$ $\mathrm{v}$ in saline supplemented with $25 \mathrm{mM}$ PIPES) for 15 minutes. Fixed cells were then washed twice more with PBS $(1 \times)$ and the coverslips were mounted onto slides using a small amount of Fluoromount ${ }^{\mathrm{TM}}$ aqueous mounting media (Sigma-Aldrich, UK). The uptake of MCT® by differentiated THP-1 cells was subsequently assessed under polarised light using light microscopy.

Determination of cell viability. The viability of differentiated THP-1 cells in the presence of MCT® containing vaccines was determined using the Presto blue colorimetric assay (Thermo Fisher Scientific, UK). Cells were treated in triplicate groups with $0,0.3,0.7, \& 2 \mathrm{mg} \mathrm{mL}{ }^{-1}$ MCT $®$ in saline for $1 \mathrm{~h}$ at $37{ }^{\circ} \mathrm{C}(5 \%$ $\mathrm{CO}_{2}$ ). Wells containing no cells were also treated with MCT® in order to assess the individual influence of this adjuvant upon the assay. Following incubation, cells were washed twice with PBS $(1 \times)$ and incubated for a further $24 \mathrm{~h}$ in the presence of Presto blue reagent (1:10 Presto blue reagent : R10 medium). The average of each triplicate set of conditions was derived from the absorbance measured at $570 \mathrm{~nm}$ following a background correction at $600 \mathrm{~nm}$ using a TECAN M200 infinite pro plate reader.

\section{Statistical analysis}

Statistical significance was determined using GraphPad Prism v.7 software, where a $p$ value of $\leq 0.05$ was indicative of a significant comparison. Before comparisons were made, the normality of datasets was analysed using a Shapiro-Wilk test. Multiple independent comparisons were made using an ANOVA followed by Tukey post hoc tests and equivalent time dependent comparisons were performed using a Friedman test followed by Dunn post hoc tests. Two-tailed unpaired $t$-tests were used to 
assess the significance of pairwise comparisons. Comparisons between particle size distributions (PSDs) were made using a Kolmogorov-Smirnov test.

\section{Results}

\section{FTIR}

The FTIR spectral characteristics of dehydrated MCT® were in good agreement with those obtained for the L-tyr standard (Fig. 1). The absorption band observed at $3199 \mathrm{~cm}^{-1}$ was attributed to the symmetric stretch of $\mathrm{NH}_{3}{ }^{+}$. Aromatic and aliphatic $\mathrm{CH}_{2}$ vibrational modes were detected in the regions 3106-3013 and 2960-2503 $\mathrm{cm}^{-1}$ respectively. $\mathrm{NH}_{3}{ }^{+}$asymmetric bending vibrations were characterised by intense adsorption bands at $1607 \& 1588 \mathrm{~cm}^{-1}$ and the in-plane aromatic $\mathrm{CH}_{2}$ bending mode located at $1513 \mathrm{~cm}^{-1}$. Both vibrational and bending modes specific to aliphatic $\mathrm{CH}_{2}$ moieties $\left(\delta \mathrm{CH}_{2}\right.$ and $\left.\omega \mathrm{CH}_{2}\right)$ and those of the phenolic ring $(\nu \mathrm{C}-\mathrm{C} \& \delta \mathrm{CH})$ were observed at $1454 \& 1363 \mathrm{~cm}^{-1}$ and 1435, 1331, 1156 and $1099 \mathrm{~cm}^{-1}$ respectively. A single band synonymous with that expected for the symmetric stretch of the phenolic $\mathrm{C}-\mathrm{O}$ bond was identified at $1246 \mathrm{~cm}^{-1}$. The region $<1000 \mathrm{~cm}^{-1}$ was populated by several wagging modes most prominently that of the aromatic $\mathrm{C}-\mathrm{H}$ bond $\left(841\right.$ and $\left.740 \mathrm{~cm}^{-1}\right)$, the amino $\mathrm{N}-\mathrm{H}$ bond $\left(803 \mathrm{~cm}^{-1}\right)$ and the carboxylic $\mathrm{OH}$ bond $\left(651 \mathrm{~cm}^{-1}\right)$.

\section{XRD}

The unrefined powder diffraction pattern of MCT® corresponded to that of L-tyr. The two diffractograms exhibited a single phase of well-resolved and narrow Bragg reflections in the region spanning $10-502 \theta^{\circ}$ (Fig. 2).

\section{TGA}

TGA curves of MCT® and L-tyr were characteristically reminiscent exhibiting a total weight loss of 95.6 and $88.7 \%$ respectively up to $800{ }^{\circ} \mathrm{C}$ and thermal stability up until $289{ }^{\circ} \mathrm{C}$ (Fig. 3). Thermographs demonstrated no significant loss of mass < $200{ }^{\circ} \mathrm{C}$. Decomposition commenced above $289{ }^{\circ} \mathrm{C}$ and was marked by a single significant phase transition, which accounted for a total weight loss of 56.5 and $40.0 \%$ respectively. The remaining mass (39.1 and $49.1 \%$ respectively) was eliminated gradually above $317^{\circ} \mathrm{C}$.

\section{TEM}

MCT® presented as a heterogeneous collection of crystalline needles, whose sizes ranged from $c a .4$ to $>10 \mu \mathrm{m}$ in length (Fig. 4). Larger needles were composed of several smaller rodlike entities each exhibiting a similar structural orientation. The presence of void spaces and crevasses within clustered formations was also observed (Fig. 4A), although the latter was often isolated to the peripheral areas/tips of the structure (Fig. 4C).

\section{Particle size determination}

Fluorescence quantification of populations < ca. $5 \mu \mathrm{m} \mathrm{vs.}$ adjuvant concentration. Preliminary studies revealed that contributions from the phenol additive within MCT® vaccines precluded the accurate quantification of soluble tyrosine within filtrates obtained from formulations containing $\geq 10 \mathrm{mg} \mathrm{mL}^{-1}$
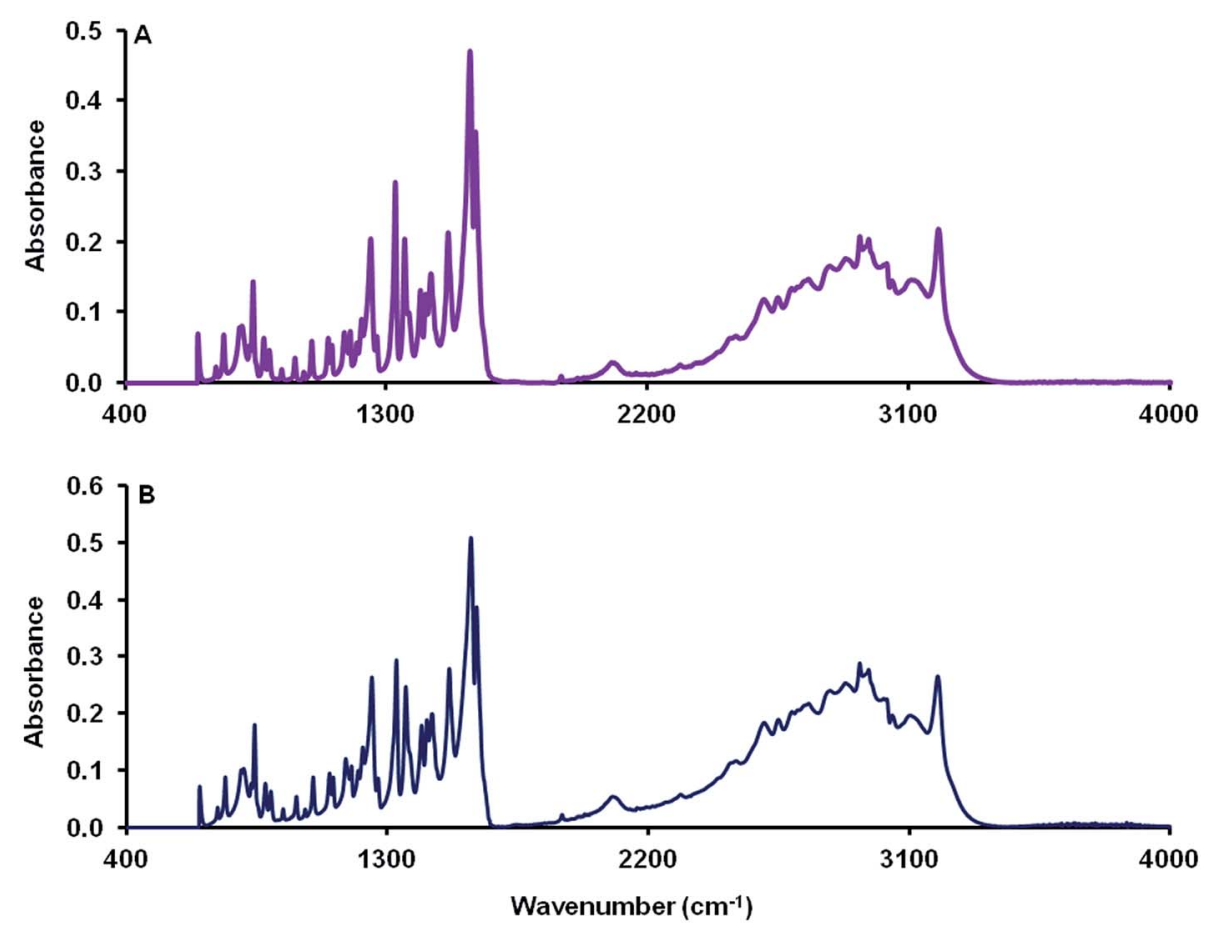

Fig. 1 FTIR spectra of MCT® (A) and L-tyr (B) determined over the range $4000-600 \mathrm{~cm}^{-1}$. 

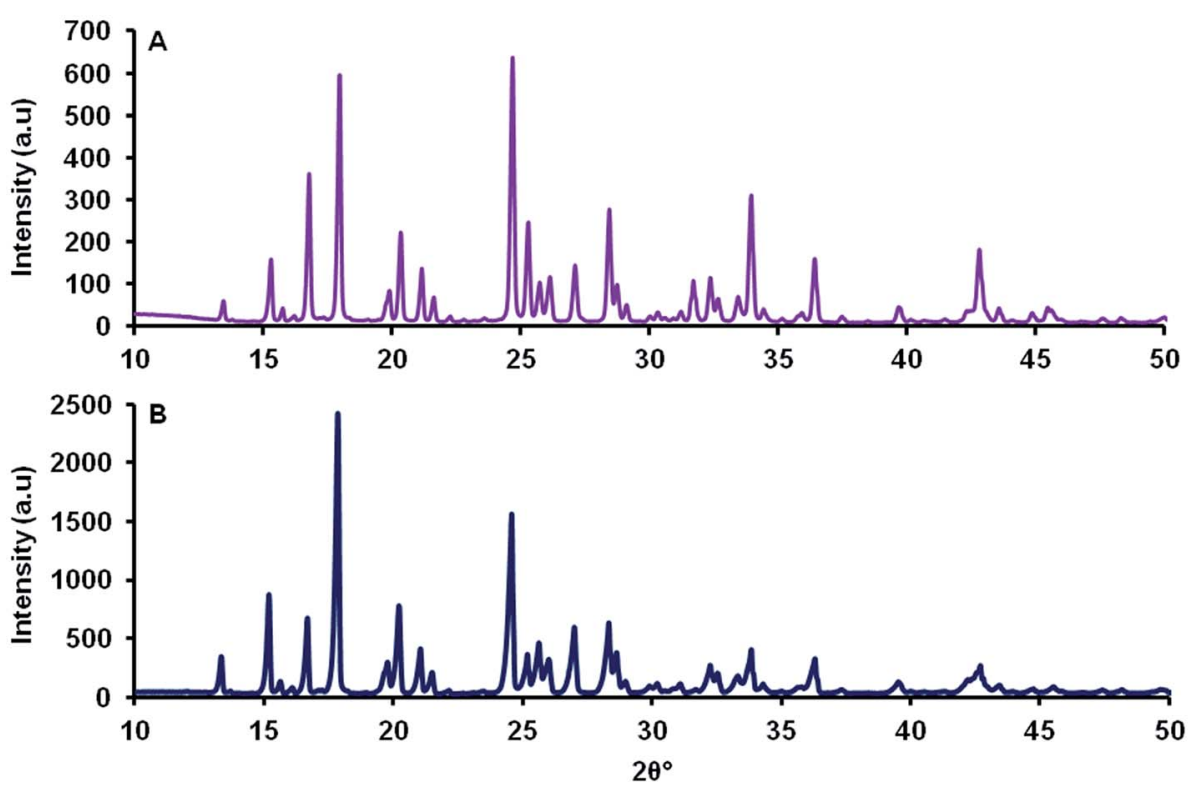

Fig. 2 Unrefined powder diffraction patterns of MCT® (A) and L-tyr (B) determined over the range 10-50 2 $\theta^{\circ}$.
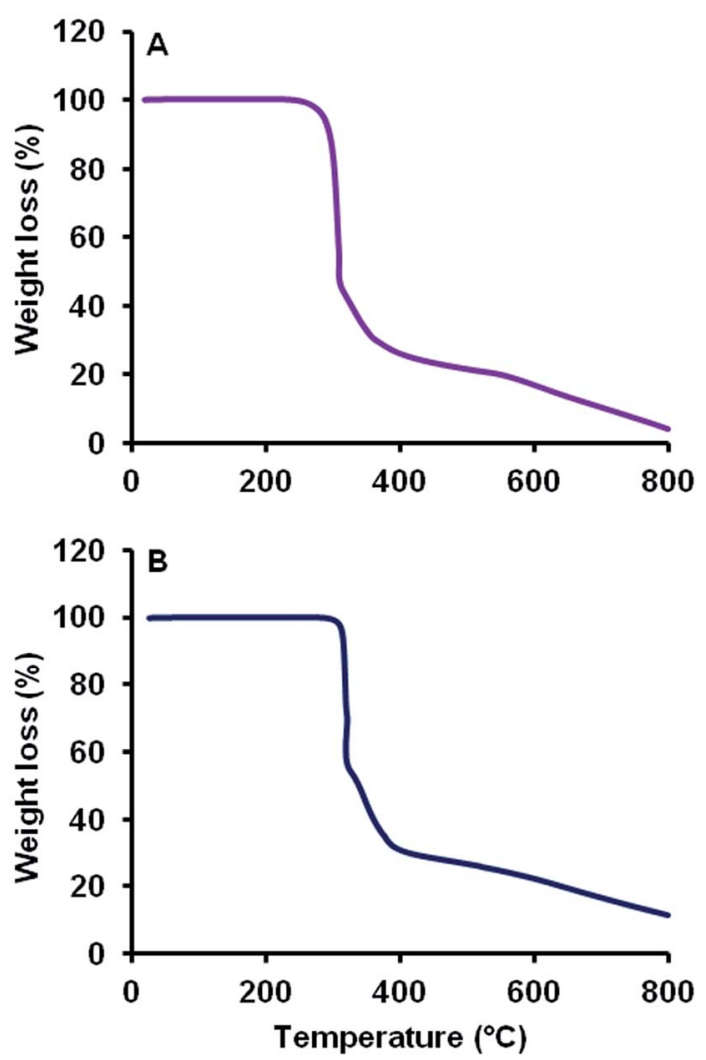

Fig. 3 TGA thermographic profiles of MCT® $(A)$ and L-tyr (B) determined from $20-800{ }^{\circ} \mathrm{C}$.

MCT® (data not shown). In order to eliminate interference of this nature, MCT® was replaced by L-tyr in all subsequent fluorescence quantification experiments.
A substantial elevation in the recovery of $\mathrm{L}$-tyr particulates $>c a$. $5 \mu \mathrm{m}$ in size was evident as the concentration of the adjuvant increased beyond that of its average solubility in saline $\left(0.39 \pm 0.03 \mathrm{mg} \mathrm{mL}^{-1}\right)$ (Fig. $\left.5 \mathrm{~A}\right)$. Indeed, at a concentration of $0.3 \mathrm{mg} \mathrm{mL} \mathrm{m}^{-1}$, L-tyr was present in an entirely soluble format within the vaccine preparation as demonstrated by the near complete recovery observed $<c a .0 .1 \mu \mathrm{m}\left(0.28 \pm 0.01 \mathrm{mg} \mathrm{mL}^{-1}\right.$, 99.6\%). Above this threshold, the amount of tyrosine $<c a .5 \mu \mathrm{m}$ in size remained fairly consistent $(0.39 \pm 0.01-0.42 \pm 0.01 \mathrm{mg}$ $\mathrm{mL}^{-1}$ ), although the majority of tyrosine detected was below $<0.1 \mu \mathrm{m}$ and thus considered soluble $(0.33 \pm 0.003-0.42 \pm$ $0.01 \mathrm{mg} \mathrm{mL}^{-1}$ ) (Fig. 5B). Furthermore, particles between 5-0.1 $\mu \mathrm{m}$ were present in trace amounts in all vaccines analysed $(1 \pm$ 1-5 $\left.\pm 2 \mu \mathrm{g} \mathrm{mL}^{-1}\right)$, only increasing in abundance in filtrates obtained from the highest concentration used in this study (79 $\pm 11 \mu \mathrm{g} \mathrm{mL}^{-1}$ ) (Fig. 5C).

Fluorescence quantification of populations <ca. $5 \mu \mathrm{m}$ : MCT® + OVA. A slight but statistically insignificant increase in the abundance of particles $>c a$. $5 \mu \mathrm{m}$ in size was noted in filtrates obtained from vaccines containing OVA $v s$. that derived from adjuvant only preparations $(0.39 \pm 0.03 v s$. $0.33 \pm 0.01, P=$ 0.12) (Fig. 6A). The recovery of soluble tyrosine also decreased $(0.32 \pm 0.01$ vs. $0.38 \pm 0.01, P<0.0001)$ (Fig. 6B) and was accompanied by the complete abolition of particles between $5 \&$ $0.1 \mu \mathrm{m}$ in size (Fig. 6C).

Quantification of populations $>$ ca. $5 \mu \mathrm{m}$. Microscopy derived PSDs revealed that particulate lengths in saline ranged from 7.3-95.5 $\mu \mathrm{m}$ in length, with a median size of $37.5 \mu \mathrm{m}$ (Fig. 7A). Crystalline widths were significantly smaller $(P<$ 0.0001) spanning a range of $1.4-8.5 \mu \mathrm{m}$ in size, with a median value of $4.9 \mu \mathrm{m}$ (Fig. 7B).

The addition of a model antigen to the vaccine milieu induced a significant reduction in the dimensions of MCT® crystals relative to that observed for MCT ${ }^{\circledR}$ alone $(P<0.0001)$. 


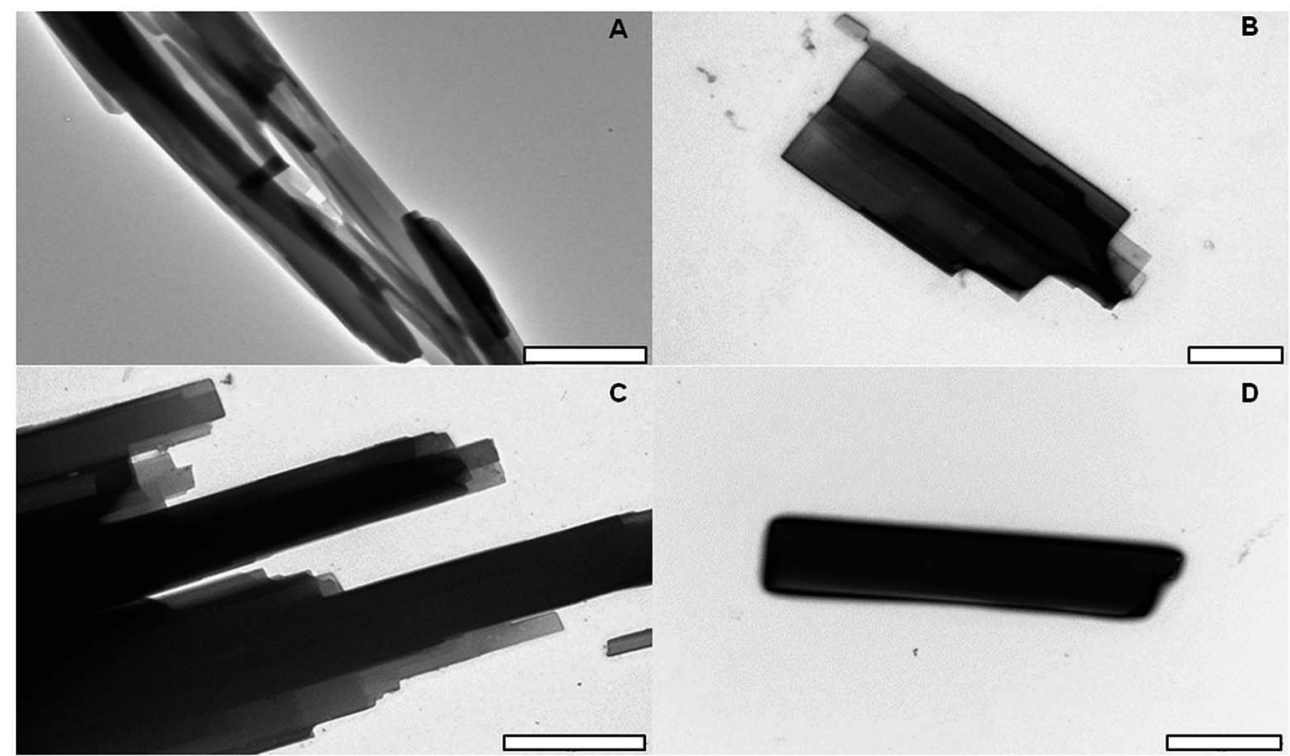

Fig. 4 TEM images of MCT® prepared at a concentration of $2 \mathrm{mg} \mathrm{mL}^{-1}$ in UPW alone (A) or in the presence of $2 \%$ uranyl acetate staining (B, $C$ and D). Images were taken at a magnification of 5,20,15 and 12k respectively and scale bars represent 5, 1 and $2 \mu \mathrm{m}$ respectively.

While the span of the distribution generated for length was comparable to that obtained for MCT® alone $(4.8-91.9 \mu \mathrm{m})$, both the interquartile range (IQR) and median size had shifted to favour lower values (11.3-31.1 $\mu \mathrm{m}$ and $18.0 \mu \mathrm{m}$ respectively).
The width of particulates in the presence of OVA also appeared smaller than those within preparations containing MCT® alone $(P<0.0001)$. Both the span and median size had decreased in this case to $1.2-5.7 \mu \mathrm{m}$ and $2.7 \mu \mathrm{m}$ respectively.
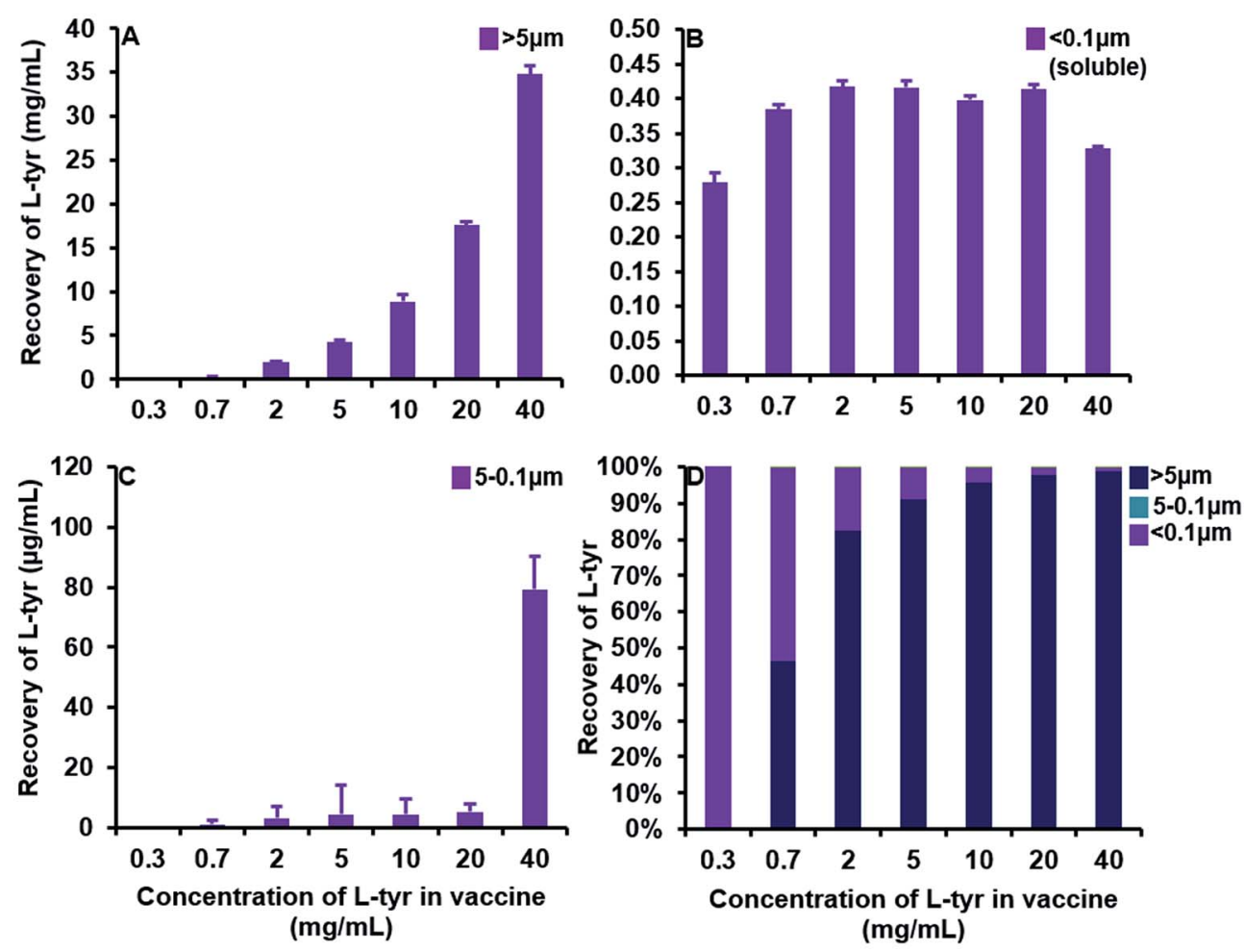

Fig. 5 Quantification of $\mathrm{L}$-tyrosine in filtrates obtained from vaccines containing $0.3-40 \mathrm{mg} \mathrm{mL}^{-1} \mathrm{~L}$-tyr formulated in saline, $\mathrm{pH} 7 \pm 0.1$. Panels (A) and (B) represent the particulate recovery $>c a .5 \mu \mathrm{m}$ and $<0.1 \mu \mathrm{m}$ (soluble) respectively. Panel (C) shows the particulate recovery between 5 and $0.1 \mu \mathrm{m}$ and panel (D) highlights the relative percentage contribution of each fraction to the whole vaccine. Error bars are representative of $\pm S D$ of the measurement where $n=5$. Data were analysed for statistical significance using an ANOVA followed by Tukey post hoc tests. 

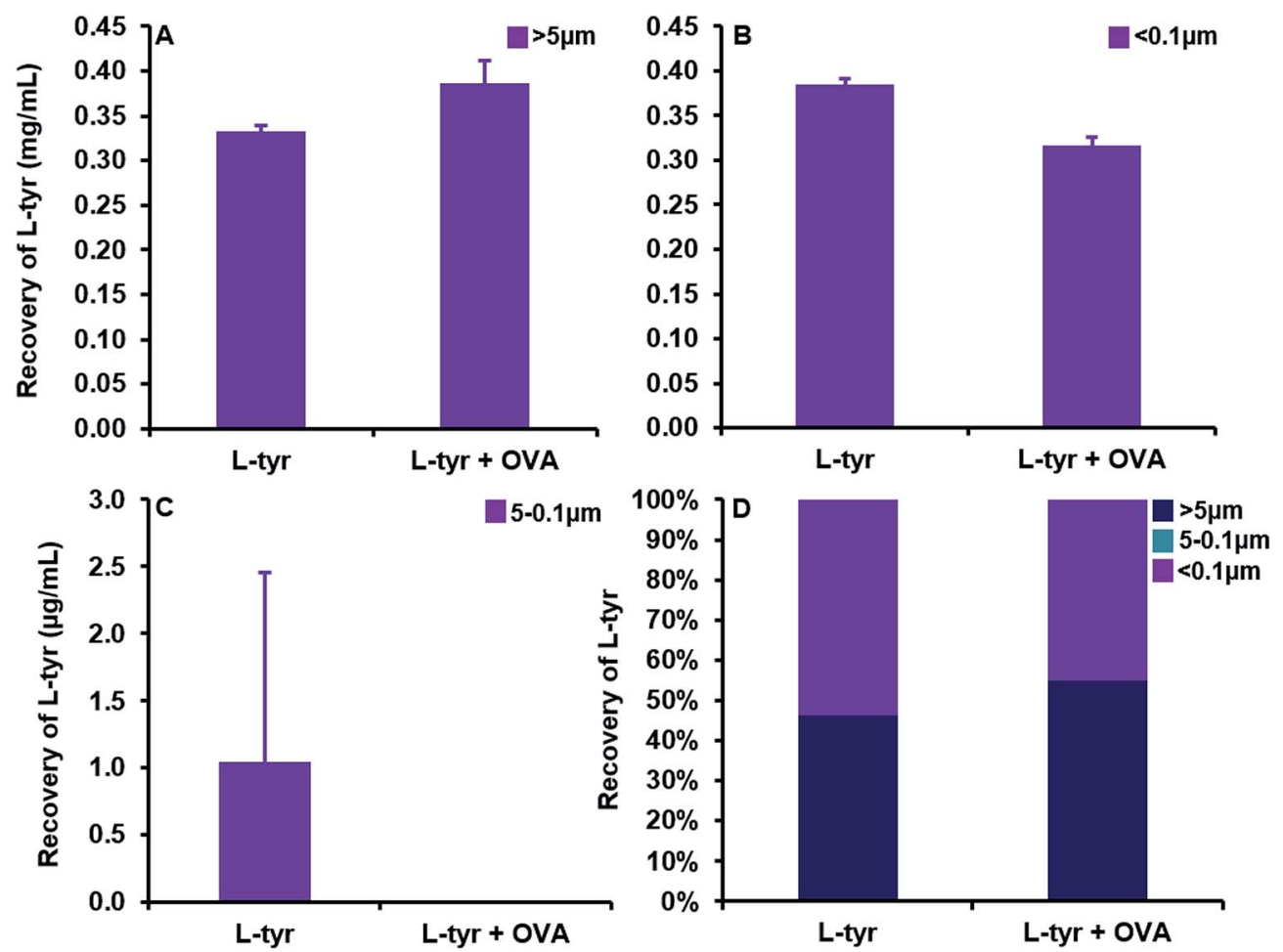

Fig. 6 Quantification of L-tyrosine in filtrates obtained from vaccines containing L-tyr $\left(0.7 \mathrm{mg} \mathrm{mL}^{-1}\right)$ and L-tyr $+\mathrm{OVA}\left(0.7 \mathrm{mg} \mathrm{mL}^{-1}+70 \mu \mathrm{g} \mathrm{mL}{ }^{-1}\right)$ formulated in saline, $\mathrm{pH} 7 \pm 0.1$. Panels (A) and (B) represent the particulate recovery $>c a .5 \mu \mathrm{m}$ and $<0.1 \mu \mathrm{m}$ (soluble) respectively. Panel (C) shows the particulate recovery between 5 and $0.1 \mu \mathrm{m}$ and panel (D) highlights the relative percentage contribution of each fraction to the whole vaccine. Error bars are representative of \pm SD of the measurement where $n=5$. Data were analysed for statistical significance using a two-tailed unpaired T-test.

Introduction of $\mathrm{MCT} \circledast$ into culture medium prompted a substantial reduction in the length of crystallites $v s$. that observed in saline, as demonstrated by the decrease in IQR and median particle size (14.9-26.3 $\mu \mathrm{m}$ and $20.8 \mu \mathrm{m}$ respectively, $P<$ 0.0001); however, the terminal values of the distribution remained similar in magnitude $(4.1-107.9 \mu \mathrm{m})$. A moderate reduction in the d50 and IQR values obtained for particulate width was also observed under these conditions $(2.8 \mu \mathrm{m}$ and $2.3-3.4 \mu \mathrm{m}$ respectively, $P<0.0001)$. Null significance was found when distributions generated for crystallite length in the presence of OVA and R10 medium were compared $(P=0.53)$; however, the latter prompted a slight decrease in crystallite width which significantly altered distribution parameters $(P<$ 0.0001 ).

Zeta potential measurements. Within physiological saline, vaccines formulated using low concentrations of MCT ${ }^{\circledR}$ exhibited a negative zeta potential $(-9.2 \pm 0.6 \mathrm{mV})$ (Fig. 8). Incorporation of antigenic material into the vaccine induced a diminutive but significant reduction in zeta potential $(-13.4$ \pm 1.0 vs. $-9.2 \pm 0.6 \mathrm{mV}, P<0.0001)$.

Solubility of MCT ${ }^{\circledR}$ in MIF. During an incubation period of 1 week within a basal MIF medium (MIF base), a total of $2.87 \pm$ $0.07 \mathrm{mg} \mathrm{mL}^{-1}$ (ca. $47 \%$ ) soluble tyrosine was liberated from the MCT ${ }^{\circledR}$ vaccine depot (Fig. 9A). This value was significantly lower than that obtained in MIF containing phosphate $\left(\mathrm{MIF} \mathrm{PO}_{4}\right)(3.17 \pm$ $\left.0.07 \mathrm{mg} \mathrm{mL}^{-1}, P=0.003\right)$ but comparable to that observed in the presence of both phosphate and citrate ions (MIF cit.) (3.04 \pm $0.08 \mathrm{mg} \mathrm{mL}^{-1}, P=0.14$ ) (Fig. 9B and $\mathrm{C}$ respectively). The average solubility of MCT ${ }^{\circledR}$ over the period of study was the highest in MIF containing phosphate $\left(0.40 \mathrm{mg} \mathrm{mL}^{-1}\right)$ and the lowest in MIF base $\left(0.36 \mathrm{mg} \mathrm{mL}{ }^{-1}\right)$. Only introduction into $\mathrm{MIF} \mathrm{PO}_{4}$ and $\mathrm{MIF}$ cit. prompted a significant initial elevation in the solubility of MCT ${ }^{\circledR}$ relative to that observed in saline following $1 \mathrm{~h}$ at $37^{\circ} \mathrm{C}(0.46 \pm$ $0.03 \mathrm{mg} \mathrm{mL} L^{-1}$ and $0.46 \pm 0.01 \mathrm{mg} \mathrm{mL}^{-1}$ respectively $v s .0 .40 \pm$ $0.004 \mathrm{mg} \mathrm{mL}^{-1}, P=0.03$ ). Linear regression analysis demonstrated that the rate of solubilisation of $\mathrm{MCT} \circledast$ over the first $4 \mathrm{~h}$ in MIF was positively influenced by the presence of both phosphate and citrate ( $P=0.02$ and 0.008 respectively) (Fig. 9D). However, comparisons between the solubilisation profiles obtained for MCT ${ }^{\circledR}$ in $\mathrm{MIF} \mathrm{PO}_{4}$ and MIF cit. over this period showed little deviation from one another $(P=0.58)$.

Cellular uptake. MCT® crystals produced a clear birefringent signal under polarised light, which assisted in the identification of both extracellular and intracellular adjuvant deposits (Fig. 10). Incidences of the latter were minimal as was the degree of cytoplasmic loading encountered i.e. one particulate per cell (Fig. 10B and C). Internalised particles were predominantly smaller than their extracellular counterparts, although particles as large as $c a .20 \mu \mathrm{m}$ were viewed in the intracellular environment. Partial phagocytosis of larger structures $(>20 \mu \mathrm{m})$, promoted through cellular interaction with needle tips was also observed (Fig. 10B). 

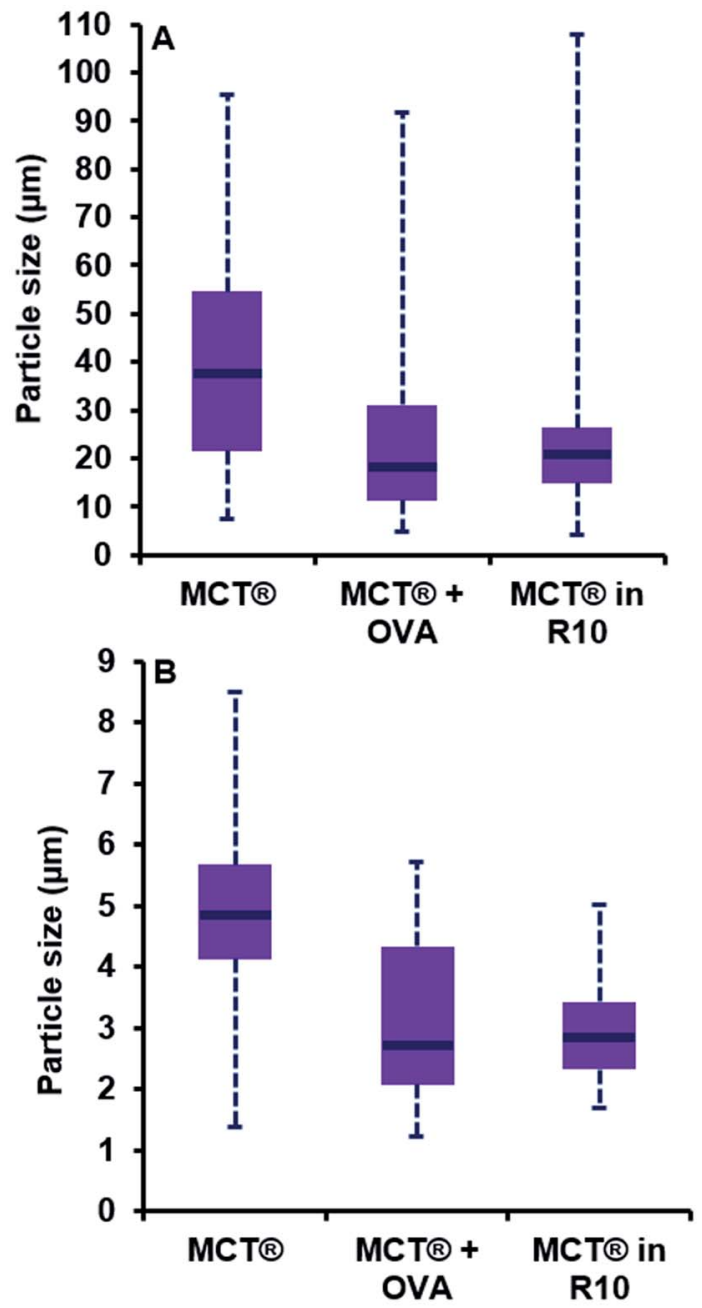

Fig. 7 Particle size distributions of $M C T \circledast$ in saline $\left(0.7 \mathrm{mg} \mathrm{mL}^{-1}\right)$, plus OVA $\left(0.7 \mathrm{mg} \mathrm{mL}^{-1}+70 \mu \mathrm{g} \mathrm{mL}^{-1}\right)$ and R10 medium $\left(2 \mathrm{mg} \mathrm{mL}^{-1}\right)$. Purple boxes represent the interquartile range of the data while blue lines show the median particle size. Blue dotted lines represent the minima and maxima of the data obtained. Panels (A) and (B) represent the distributions for the length and width of MCT $®$ particles respectively. Distributions were analysed for statistical significance using a Kolmogorov-Smirnov test.

Cell viability. The absorbance values obtained from control wells, which contained no cells + MCT®, became more prominent as the concentration of the adjuvant was increased, illustrating that higher concentrations of this material had the potential to interfere with the results of the assay (data not shown). However, background correction at $600 \mathrm{~nm}$ was sufficient to negate contributions from both residual adjuvant deposits and cellular debris. MCT ${ }^{\circledR}$ at concentrations up to $2 \mathrm{mg} \mathrm{mL}{ }^{-1}$ did not adversely influence the viability of THP-1 differentiated macrophages relative to that observed for untreated controls (>95\% viability, $P>0.9$ ) (Fig. 11).

\section{Discussion}

Vaccinological advances, including the development of safer and more effective immunopotentiating compounds, are

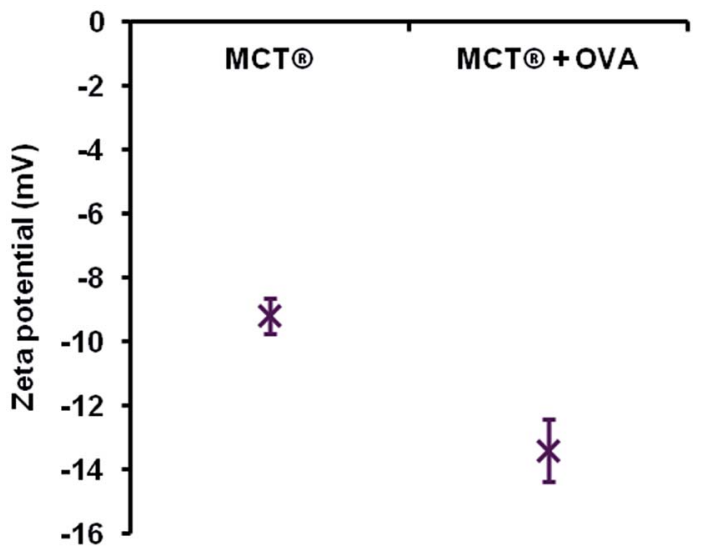

Fig. 8 Zeta potential measurements of $\mathrm{MCT} \circledast$ alone $\left(0.7 \mathrm{mg} \mathrm{mL}^{-1}\right)$ and $\mathrm{MCT} \otimes+$ OVA $\left(0.7 \mathrm{mg} \mathrm{mL}^{-1}+70 \mu \mathrm{g} \mathrm{mL}^{-1}\right)$ in saline. Error bars are representative of \pm SD of the measurement where $n=5$. Data were analysed for statistical significance using a two-tailed unpaired $T$-test.

heavily reliant on the exposition of structure-activity relationships (SARs) such as those proposed herein for MCT®. Furthermore, this is the first study to demonstrate that the physicochemical properties of MCT ${ }^{\circledR}$, play a pivotal role in the immunological processing of this adjuvant by APCs.

The IR vibrations acquired for MCT ${ }^{\circledR}$ confirmed its identity as L-tyr, revealing the presence of both structural amino and phenolic functional groups. While DFT calculations also predicted additional contributions from phenolic hydroxyl and carboxylic carbonyl groups around $3600 \& 1750 \mathrm{~cm}^{-1}$ respectively, ${ }^{52,53}$ these bands were neither detected in this study or observed by others experimentally for $\mathrm{L}$-tyr in its solid state. ${ }^{53-55}$ In this phase, $\mathrm{L}$-tyr is reported to exist in a flexible zwitterionic configuration, ${ }^{53,56}$ the structure of which is stabilised through intermolecular hydrogen bonding. ${ }^{57}$ Yadav et al. proposed that the presence of such species could be identified by the presence of a spectral combination band at $c a .2075 \mathrm{~cm}^{-1} .{ }^{53}$ Indeed, both MCT® and L-tyr yielded evidence of this band around $2077 \mathrm{~cm}^{-1}$ inferring that both samples had near identical molecular configurations.

L-tyr crystals are populated by geometrically orthorhombic unit cells, which are preferentially elongated in the direction of the $b$ axis. ${ }^{57}$ XRD analysis revealed that MCT® possessed a high degree of structural order and that reflection positioning was akin to that of L-tyr; however, unit cell parameters for both samples were not explicitly calculated herein. The resultant crystals congregated to form extensive rod-like projections, which were large and heterogeneous in length via TEM. MCT® also appeared to lack a water decomposition phase by TGA $\left(<200{ }^{\circ} \mathrm{C}\right)$, which indicated the lack of physically adsorbed moisture at the surface interface. A decrease in hydroxyl display/ surface functionality has been associated with the reduced reactivity of aluminium salts in vitro in terms of proinflammatory cytokine production, ROS generation and inflammasome activation. ${ }^{58}$ The depletion of IgE titres in vivo has also been reported following vaccination with highly crystalline materials, ${ }^{58}$ a mechanism which has been tentatively 

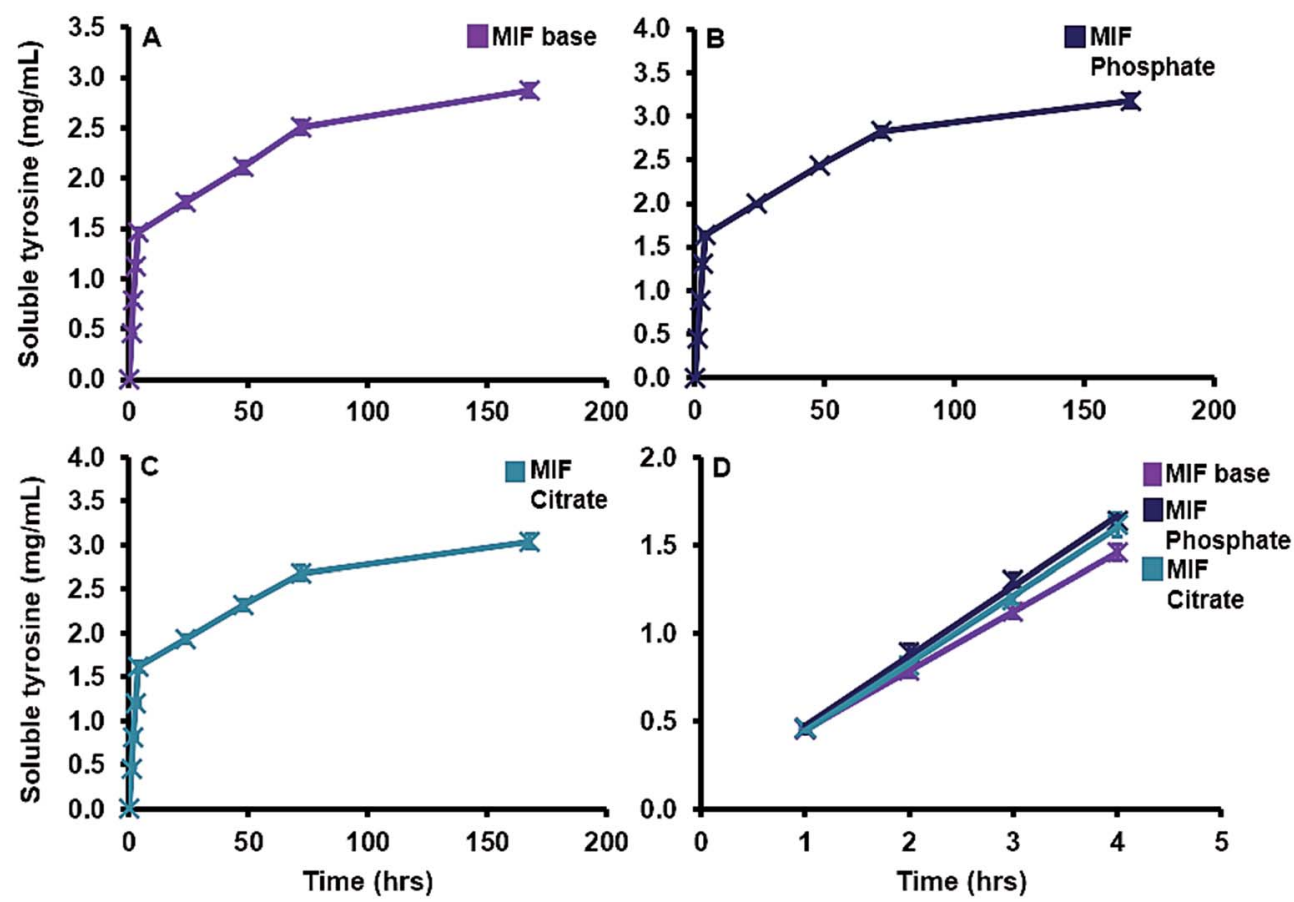

Fig. 9 Solubility profiles of MCT® vaccines in MIF over a period of $168 \mathrm{~h}$ at $37^{\circ} \mathrm{C}, \mathrm{pH} 7.4 \pm 0.05$. Panel (A) shows the solubility of MCT® in MIF base (purple lines) while panels (B) and (C) highlight its solubility in MIF phosphate and MIF citrate respectively (blue and green lines respectively). Panel (D) compares the initial rate of solubilisation of MCT® in the various formulations of MIF using a linear regression analysis. Error bars are representative of \pm SD of the measurement where $n=5$. Data were analysed for statistical significance using a Friedman test followed by Dunn post hoc tests.

linked to the suppression of IL-18 secretion. ${ }^{47}$ While further studies are required in order to fully validate these suppositions, these SARs may provide an initial explanation regarding the ability of MCT® to promote the class-switch recombination mechanisms required to ameliorate allergic responses whilst minimising local side-effects following administration.

One documented advantage of MCT ${ }^{\circledR}$ in SCIT as oppose to traditional aluminium salts is its rapid relative elimination from the site of injection via the bloodstream, typically within one week of administration. ${ }^{33}$ The solubility of MCT ${ }^{\circledR}$ in model interstitial fluid was between $0.36-0.4 \mathrm{mg} \mathrm{mL}^{-1}$ and its rate of dissolution was predominantly volume dependent, as evidenced by the consistency of values obtained per time point. While these values are marginally lower than the documented solubility of $\mathrm{L}$-tyr in aqueous solution $\left.(0.45 \mathrm{mg} \mathrm{mL})^{-1}\right)^{59}$ increasing the ionic strength of the surrounding environment has been shown to decrease the solubility of this amino acid. ${ }^{60}$ The solubility of MCT® was also moderately increased in the presence of phosphate and citrate ions; however, due to methodological constraints, contributions from serum proteins were not considered in this study. Such contributions are of particular importance with regards to the formation of proteinaceous coronas, which may provide some protection against ligandinduced solubility in vivo. This may be beneficial with regards to the conservation of the adjuvant depot, increasing the amount of material available to interact with infiltrating granulocytes and APCs, the recruitment of which has been observed as early as $4 \mathrm{~h}$ post immunisation with MCT®-adjuvanted vaccines. ${ }^{61}$ Furthermore, an increase in cell-mediated translocation of antigen/antigen-adjuvant complexes to lymph nodes may serve to facilitate vaccine priming, an essential prerequisite for the development of robust adaptive immune responses. ${ }^{62}$

The hydrodynamic size of particles within the adjuvant bolus directly influences the rate at which they are removed from the injection site by infiltrating phagocytes, with particles between 1-3 $\mu \mathrm{m}$ in size being considered optimal for recognition and engulfment by macrophages. ${ }^{63-65}$ Within saline the proportion of particles approximately corresponding to this range (0.1-5 $\mu \mathrm{m}$ ) was consistently minimal (max. $79.3 \mu \mathrm{g} \mathrm{mL} \mathrm{mL}^{-1} \mathrm{~L}$-tyr) and the addition of model antigen resulted in a near complete abolition of this population. These observations indicate that the abundance of particulates within this range was somewhat independent of adjuvant concentration but was significantly decreased in the presence of small amounts of antigen; however, whether such correlations exist for particles exceeding $5 \mu \mathrm{m}$ is currently unclear without the use of sizing methodologies with both greater resolution and upper limits of detection. Furthermore, the large hydrodynamic length of MCT® crystals in biological medium $(>c a .10 \mu \mathrm{m})$ appeared to partially stymie the scavenging capacity of THP-1 macrophages in vitro, as demonstrated by the limited incidence of crystals located within the cytoplasm of these model phagocytes following brief exposure. This is in stark contrast to results obtained using a crystalline aluminium adjuvant (Fig. S3†) where it's optimal particle size (median size - $1.4 \mu \mathrm{m}$ (Fig. S2 $\dagger$ )) appeared to 


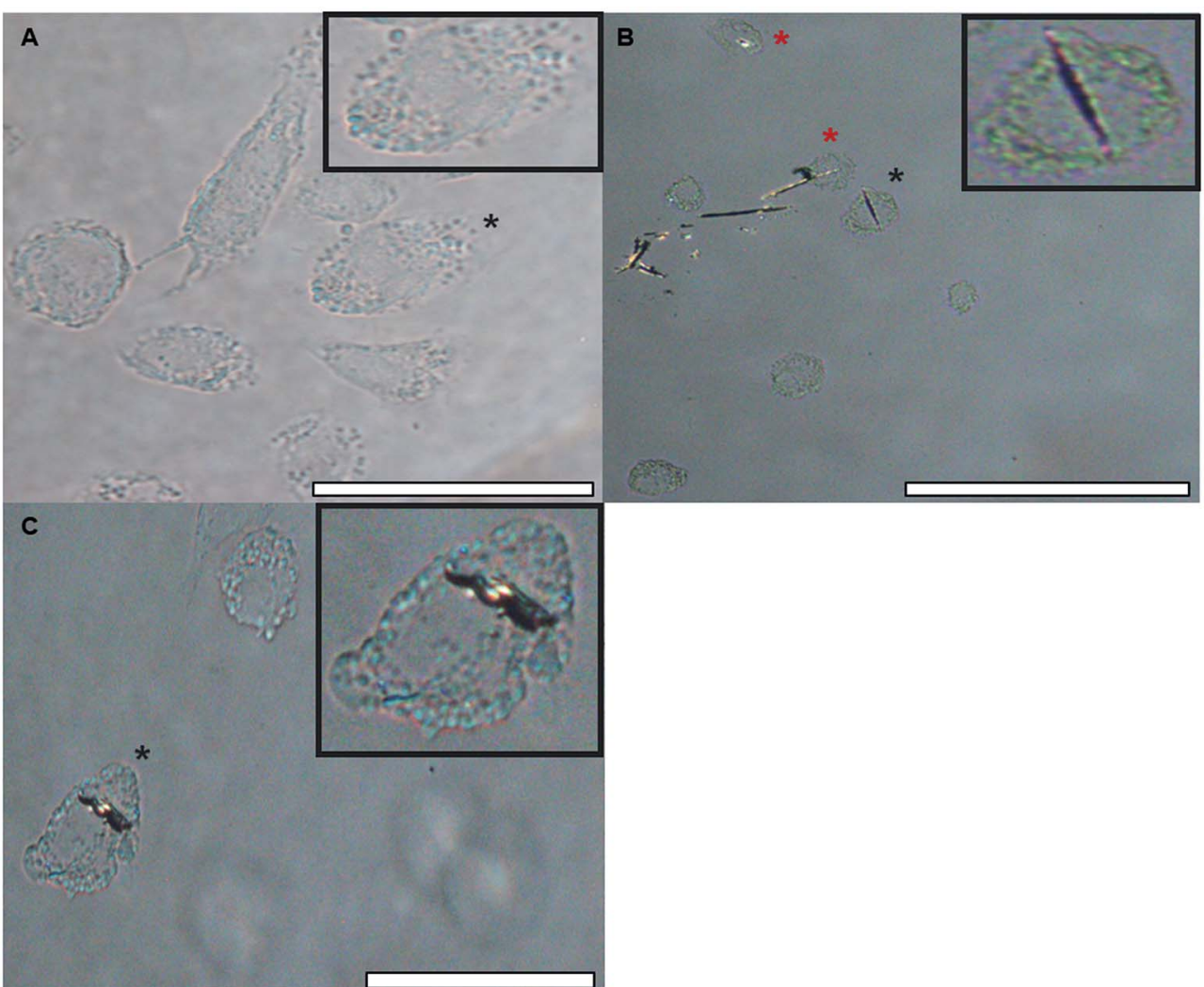

Fig. 10 Light images of native THP-1 differentiated macrophages in R10 medium ((A), mag. 400×, scale bar $50 \mu \mathrm{m})$ and those treated with MCT® $\left(2 \mathrm{mg} \mathrm{mL}^{-1}\right)$ for $1 \mathrm{~h}$ (B and C). Images (B) and (C) were taken under polarised light at a magnification of 200 and $400 \times$ respectively (scale bars 100 and $50 \mu \mathrm{m}$ respectively). The cells used as inserts are identified by a black asterisk. Those highlighted by red and black asterisks in panels $B$ \& $C$ appear to demonstrate some element of adjuvant loading.

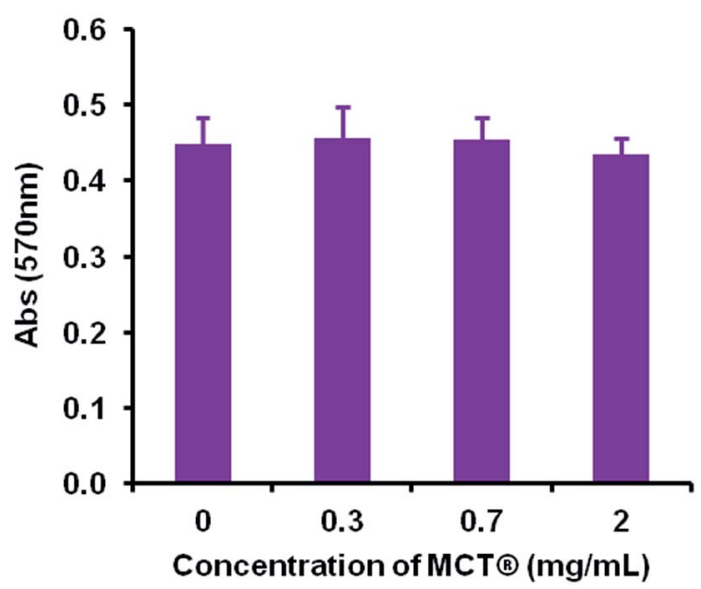

Fig. 11 Viability of THP-1 differentiated macrophages in the presence of various concentrations $\left(0.3-2 \mathrm{mg} \mathrm{mL}^{-1}\right)$ of $\mathrm{MCT} \circledast$ after $24 \mathrm{~h}$ incubation at $37^{\circ} \mathrm{C}$. Cell viability was measured using the Presto blue assay at a wavelength of $570 \mathrm{~nm}$. Error bars represent the \pm SD of the measurement where $n=4$. Data were analysed for statistical significance using an ANOVA followed by Tukey post hoc tests.

facilitate cytoplasmic loading to the point of near saturation in the majority of cells over the same period of incubation (Fig. S4 $\dagger$ ). Such observations emphasise that size-related parameters present a significant impediment with regards to the aggregate cellular recognition and uptake of MCT® under in vitro conditions.

However, despite these obvious limitations, perpendicular contact with needle peripheries, whose dimensions were substantially smaller (median width $-2.8 \mu \mathrm{m}$ ), appeared to result in both partial and complete phagocytosis of adjuvant material, although further investigations are required in order to unequivocally confirm this. Such events did not induce any significant changes in the metabolic activity of macrophages confirming that these interactions did not adversely influence cell viability at the concentrations studied herein. This prospective mechanism of uptake is consistent with that observed for ellipsoidal particles, where the kinetics and success of internalisation showed a greater dependency upon the eccentricity of the contact site than particulate volume. ${ }^{66,67}$ Interestingly, microscopic and ELS analysis indicated that a small amount of antigenic adsorption also preferentially occurred at these sites (Fig. S1†) irrespective of the negative zeta potential values obtained for both OVA and MCT®. However, the binding capacity and affinity of antigens for these particular sites does require further investigation before definitive conclusions can be drawn. Nevertheless, it is highly probable that the terminals of MCT ${ }^{\circledR}$ crystals act as a scaffold for the direct presentation of antigen to APCs. These observations infer 
that MCT® may play an active role in the enhancement of MHC class II expression and prevention of proteolytic degradation in the lysosomal compartment, both of which have been shown to improve the immunogenicity of vaccine formulations in vivo. ${ }^{42,46,68}$

As mentioned previously, the negative zeta potential of MCT® limited the interfacial adsorption of a model antigen bearing the same charge i.e. OVA. Negatively charged adjuvants have been routinely employed to attenuate the affinity of antigen-adjuvant complexes through electrostatic mechanisms, which serves to induce a more robust immunological response post immunisation. ${ }^{69-73}$ However, it is debatable how useful this would be specifically in the case of SCIT, where the success of individual treatments appears to be somewhat dependent upon the prolonged retention and gradual release of allergens at the site of injection. ${ }^{35}$ Heightened retention of weakly associated antigens is possible, however, through the entrapment of these proteinaceous species within adjuvant void spaces. ${ }^{73}$ This mechanism combined with the sparing solubility of MCT ${ }^{\circledR}$ at the injection site may provide a convincing explanation as to how this adjuvant can act as an antigen depot in formulations possessing low adsorption coefficients.

While the influence of adjuvant zeta potential upon the adsorption of proteins within biological fluid remains equivocal, anionic particles have been shown to be more effectively opsonised through the adsorption of serum immunoglobulins. ${ }^{74}$ Such events have been shown to increase the internalisation but not the recognition of micron-sized entities by macrophages in vitro through FcR-mediated phagocytosis. ${ }^{75}$ However, the study concluded that these trends were not applicable to larger particles. ${ }^{75}$ It is therefore unlikely that opsonisation could enhance the uptake of MCT® in vivo.

\section{Conclusions}

This study has revealed that the physicochemical properties of MCT® contribute to the recognition of this material by APCs in vitro. While these data are preliminary in nature, the substantial size of crystallites appeared to be a limiting factor with regards to their recognition and uptake by THP-1 macrophages, at least following short term exposure. However, it is plausible that the solubility of MCT® in interstitial fluid will facilitate a gradual decrease in the size of adjuvant particles and thus increase the likelihood of particulate recognition by infiltrating immune cells. Such observations imply that the therapeutic modus operandi of MCT ${ }^{\circledR}$ may involve some element of direct antigen presentation to APCs and cell-mediated migration to the draining lymph nodes, although confirmation of this requires further investigation. In conjunction, these mechanisms may serve to explain how MCT® potentiates a robust immunological response in SCIT despite exhibiting a theoretically low reactivity in situ.

\section{Funding}

This research was funded by Bencard Allergie GmbH.

\section{Conflicts of interest}

$\mathrm{CE}$ is in receipt of a grant from Bencard Allergie (the manufacturers of MCT $\left.{ }^{\circledR}\right)$ to support this research.

\section{Acknowledgements}

Dr Matthew Heath (Allergy Therapeutics) and Prof. Matthias Kramer (Bencard Allergie) are thanked for their helpful advice regarding the manuscript. Dr Matthew Mold (Keele University) is thanked for his help with light microscopy and TEM data acquisition. Cátia Freitas and Martin Jendrlin (Keele University) are both thanked for their help with XRD and TGA data acquisition.

\section{References}

1 J. M. Rolland, L. M. Gardner and R. E. O'Hehir, Functional regulatory $\mathrm{T}$ cells and allergen immunotherapy, Curr. Opin. Allergy Clin. Immunol., 2010, 10, 559-566.

2 G. Blumberga, L. Groes and R. Dahl, SQ-standardized house dust mite immunotherapy as an immunomodulatory treatment in patients with asthma, Allergy, 2011, 66, 178185.

3 A. Yukselen, S. G. Kendirli, M. Yilmaz, D. U. Altintas and G. B. Karakoc, Effect of One-Year Subcutaneous and Sublingual Immunotherapy on Clinical and Laboratory Parameters in Children with Rhinitis and Asthma: A Randomized, Placebo-Controlled, Double-Blind, DoubleDummy Study, Int. Arch. Allergy Immunol., 2012, 157, 288298.

4 D. Zhao, X. Lai, M. Tian, Y. Jiang, Y. Zheng, B. Gjesing, N. Zhong and M. D. Spangfort, The Functional IgEBlocking Factor Induced by Allergen-Specific Immunotherapy Correlates with IgG4 Antibodies and a Decrease of Symptoms in House Dust Mite-Allergic Children, Int. Arch. Allergy Immunol., 2016, 169, 113-120.

5 M. Wyss, T. Scheitlin, B. M. Stadler and B. Wüthrich, Immunotherapy with aluminum hydroxide adsorbed insect venom extracts (Alutard SQ): immunologic and clinical results of a prospective study over 3 years, Allergy, 1993, 48, 81-86.

6 M. Albanesi, A. Nico, A. Sinisi, L. Giliberti, M. P. Rossi, M. Rossini, G. Kourtis, A. S. Rucco, F. Loconte, L. Muolo, M. Zurlo, D. Di Bona, M. F. Caiaffa and L. Macchia, A 13year real-life study on efficacy, safety and biological effects of Vespula venom immunotherapy, Clin. Mol. Allergy, 2018, $16,2$.

7 H. W. Baenkler, S. Meußer-Storm and G. Eger, Continuous immunotherapy for hymenoptera venom allergy using six month intervals, Allergol. Immunopathol., 2005, 33, 7-14.

8 M. C. Pereira Santos, E. Pedro, A. Spínola Santos, M. Branco Ferreira, M. L. Palma Carlos and A. G. Palma Carlos, Immunoblot studies in allergic patients to hymenoptera venom before and during immunotherapy, Eur Ann Allergy Clin Immunol, 2005, 37, 273-278. 
9 M. C. Pereira Santos, A. P. Baptista, A. Melo, R. R. Alves, R. S. Soares, E. Pedro, M. Pereira Barbosa, R. M. Victorino and A. E. Sousa, Expansion of circulating Foxp3+CD25bright CD4+ $\mathrm{T}$ cells during specific venom immunotherapy, Clin. Exp. Allergy, 2007, 38, 291-297.

10 J. Cox and A. Coulter, Adjuvants - a classification and review of their modes of action, Vaccine, 1997, 15, 248-256.

11 R. K. Gupta, Aluminum compounds as vaccine adjuvants, Adv. Drug Delivery Rev., 1998, 32, 155-172.

12 P. Moingeon, Adjuvants for allergy vaccines, Hum. Vaccines Immunother., 2012, 8, 1492-1498.

13 C. Exley, Aluminium adjuvants and adverse events in subcutaneous allergy immunotherapy, Allergy, Asthma, Clin. Immunol., 2014, 10, 4.

14 E. B. Lindblad, Aluminium compounds for use in vaccines, Immunol. Cell Biol., 2004, 82, 497-505.

15 K. L. Goldenthal, J. A. Cavagnaro, C. Alving and F. R. Vogel, Safety evaluation of vaccine adjuvants. NCVDG working groups, AIDS Res. Hum. Retroviruses, 1993, 9, s47-s51.

16 L. El-Shabrawi-Caelen, P. Poelt, W. Aberer and E. Aberer, Progressive circumscribed sclerosis-a novel side-effect of immunotherapy with aluminium-adsorbed allergen extracts, Allergy, 2009, 64, 961-967.

17 B. Kreft, M. Bednarczyk, F. Emmerling and W. C. Marsch, Cutaneous-subcutaneous pseudolymphoma after specific immunotherapy with grass-rye pollen-allergen extract containing aluminium hydroxide, Advances in Dermatology and Allergology, 2011, 28, 134-137.

18 C. C. Ronit and G. Arnon, Allergen immunotherapy-induced biphasic systemic reactions: incidence, characteristics, and outcome: a prospective study, Ann. Allergy, Asthma, Immunol., 2010, 104, 73-78.

19 H. Chong, K. Brady, D. Metze and E. Calonje, Persistent nodules at injection sites (aluminium granuloma) clinicopathological study of 14 cases with a diverse range of histological reaction patterns, Histopathology, 2006, 48, 182-188.

20 E. Netterlid, M. Hindsén, J. Björk, S. Ekqvist, N. Güner, K. A. Henricson and M. Bruze, There is an association between contact allergy to aluminium and persistent subcutaneous nodules in children undergoing hyposensitization therapy, Contact Dermatitis, 2009, 60, 4149.

21 M. G. Ozden, M. Kefeli, F. Aydin, N. Senturk, T. Canturk and A. Y. Turanli, Persistent subcutaneous nodules after immunotherapy injections for allergic asthma, J. Cutaneous Pathol., 2009, 36, 812-814.

22 T. Hansen, L. Klimek, F. Bittinger, I. Hansen, F. Capitani, A. Weber, A. Gatti and C. J. Kirkpatrick, Mastzellreiches aluminiumgranulom, Pathologe, 2008, 29, 311-314.

23 F. Musa, M. Al-Ahmad, N. Arifhodzic and W. Al-Herz, Compliance with allergen immunotherapy and factors affecting compliance among patients with respiratory allergies, Hum. Vaccines Immunother., 2017, 13, 514-517.

24 J. L. Grun and P. H. Maurer, Different T helper cell subsets elicited in mice utilizing two different adjuvant vehicles: the role of endogenous interlukin-1 in proliferative responses, Cell. Immunol., 1989, 121, 134-145.

25 J. M. Brewer, M. Conacher, A. Satoskar, H. Bluethmann and J. Alexander, In Interleukin-4-deficient mice, alum not only generates $\mathrm{T}$ helper 1 responses equivalent to freund's complete adjuvant, but continues to induce $\mathrm{T}$ helper 2 cytokine production, Eur. J. Immunol., 1996, 26, 2062-2066.

26 M. B. Jordan, D. M. Mills, J. Kappler, P. Marrack and J. C. Cambier, Promotion of B cell immune responses via an alum-induced myeloid cell population, Science, 2004, 304, 1808-1810.

27 P. Victoratos, M. Yiangou, N. Avramidis and L. Hadjipetrou, Regulation of cytokine gene expression by adjuvants in vivo, Clin. Exp. Immunol., 1997, 109, 569-578.

28 M. Rosewich, D. Lee and S. Zielen, Pollinex Quattro: an innovative four injections immunotherapy in allergic rhinitis, Hum. Vaccines Immunother., 2013, 9, 1523-1531.

29 S. Zielen, J. Gabrielpillai, E. Herrmann, J. Schulze, R. Schubert and M. Rosewich, Long-term effect of monophosphoryl lipid A adjuvanted specific immunotherapy in patients with grass pollen allergy, Immunotherapy, 2018, 10, 529-536.

30 M. D. Heath, N. J. Swan, A. C. Marriott, N. J. Silman, B. Hallis, C. Prevosto, K. E. Gooch and M. A. Skinner, Comparison of a novel microcrystalline tyrosine adjuvant with aluminium hydroxide for enhancing vaccination against seasonal influenza, BMC Infect. Dis., 2017, 17, 232.

31 G. Cabral Miranda, M. D. Heath, A. C. Gomes, M. O. Mohsen, E. Montoya Diaz, A. M. Salman, E. Atcheson, M. A. Skinner, M. F. Kramer, A. Reyes Sandoval and M. F. Bachmann, Microcrystalline Tyrosine (MCT®): A Depot Adjuvant in Licensed Allergy Immunotherapy Offers New Opportunities in Malaria, Vaccines, 2017, 5, 32.

32 D. G. Maggs, R. Jacob, F. Rife, R. Lange, P. Leone, M. J. During, W. V. Tamborlane and R. S. Sherwin, Interstitial fluid concentrations of glycerol, glucose, and amino acids in human quadricep muscle and adipose tissue. Evidence for significant lipolysis in skeletal muscle, J. Clin. Invest., 1995, 96, 370-377.

33 A. C. M. L. Miller, A. P. Hart and E. C. D. Tees, Pteronyssinustyrosine adsorbate: biological and clinical properties, Acta Allergol., 1976, 31, 35-43.

34 P. Baldrick, D. Richardson and A. W. Wheeler, Review of Ltyrosine confirming its safe human use as an adjuvant, $J$. Appl. Toxicol., 2002, 22, 333-344.

35 A. W. Wheeler, D. M. Moran, B. E. Robins and A. Driscoll, LTyrosine as an immunological adjuvant, Int. Arch. Allergy Appl. Immunol., 1982, 69, 113-119.

36 S. C. Eisenbarth, O. R. Colegio, W. O'Connor, F. S. Sutterwala and R. A. Flavell, Crucial role for the Nalp3 inflammasome in the immunostimulatory properties of aluminium adjuvants, Nature, 2008, 453, 1122-1126.

37 H. Li, S. B. Willingham, J. P. Ting and F. Re, Cutting edge: inflammasome activation by alum and alum's adjuvant effect are mediated by NLRP3, J. Immunol., 2008, 181, 17-21.

38 M. Kool, V. Petrilli, T. De Smedt, A. Rolaz, H. Hammad, M. Van Nimwegen, I. M. Bergen, R. Castillo, 
B. N. Lambrecht and J. Tschopp, Cutting edge: alum adjuvant stimulates inflammatory dendritic cells through activation of the NALP3 inflammasome, J. Immunol., 2008, 181, 3755-3759.

39 F. A. Sharp, D. Ruane, B. Claass, E. Creagh, J. Harris, P. Malyala, M. Singh, D. T. O'Hagan, V. Pétrilli, J. Tschopp, L. A. O'Neill and E. C. Lavelle, Uptake of particulate vaccine adjuvants by dendritic cells activates the NALP3 inflammasome, Proc. Natl. Acad. Sci. U. S. A., 2009, 106, 870-875.

40 A. T. Glenny, G. A. H. Buttle and M. F. Stevens, Rate of disappearance of diphtheria toxoid injected into rabbits and guinea-pigs: toxoid precipitated with alum, J. Pathol. Bacteriol., 1931, 34, 267-275.

41 L. B. Holt, Developments in Diphtheria Prophylaxis, Heinemann Ltd, London, UK, 1950.

42 J. W. Mannhalter, H. O. Neychev, G. J. Zlabinger, R. Ahmad and M. M. Eibl, Modulation of the human immune response by the non-toxic and non-pyrogenic adjuvant aluminium hydroxide: effect on antigen uptake and antigen presentation, Clin. Exp. Immunol., 1985, 61, 143-151.

43 G. L. Morefield, A. Sokolovska, D. Jiang, H. HogenEsch, J. P. Robinson and S. L. Hem, Role of aluminumcontaining adjuvants in antigen internalization by dendritic cells in vitro, Vaccine, 2005, 23, 1588-1595.

44 M. Mold, M. Kumar, A. Mirza, E. Shardlow and C. Exley, Intracellular tracing of amyloid vaccines through direct fluorescent labelling, Sci. Rep., 2018, 8, 2437.

45 T. R. Ghimire, R. A. Benson, P. Garside and J. M. Brewer, Alum increases antigen uptake, reduces antigen degradation and sustains antigen presentation by DCs in vitro, Immunol. Lett., 2012, 147, 55-62.

46 H. Sun, K. G. Pollock and J. M. Brewer, Analysis of the role of vaccine adjuvants in modulating dendritic cell activation and antigen presentation in vitro, Vaccine, 2003, 21, 849-855.

47 E. Shardlow, M. Mold and C. Exley, Unraveling the enigma: elucidating the relationship between the physicochemical properties of aluminium-based adjuvants and their immunological mechanisms of action, Allergy, Asthma, Clin. Immunol., 2018, 14, 80.

48 M. Mold, L. Ouro-Gnao, B. Wieckowski and C. Exley, Copper prevents amyloid- $\beta 1-42$ from forming amyloid fibrils under near-physiological conditions in vitro, Sci. Rep., 2013, 3, 1256-1262.

49 N. Fogh-Andersen, B. M. Altura, B. T. Altura and O. SiggaardAndersen, Composition of interstitial fluid, Clin. Chem., 1995, 41, 1522-1525.

$50 \mathrm{~S}$. Seeber, J. White and S. Hem, Solubilization of aluminiumcontaining adjuvants by constituents of interstitial fluid, $J$. Parenter. Sci. Technol., 1991, 45, 156-159.

51 M. E. Lund, J. To, B. A. O'Brien and S. Donnelly, The choice of phorbol 12-myristate 13-acetate differentiation protocol influences the response of THP-1 macrophages to a proinflammatory stimulus, J. Immunol. Methods, 2016, 30, 6470.

52 R. Ramaekers, J. Pajak, M. Rospenk and G. Maes, Matrixisolation FT-IR spectroscopic study and theoretical
DFT(B3LYP)/6-31++G** calculations of the vibrational and conformational properties of tyrosine, Spectrochim. Acta, Part A, 2005, 61, 1347-1356.

53 R. A. Yadav, V. Dixit, M. Yogesh and C. Santhosh, Raman and IR Spectral and DFT Based Vibrational and Electronic Characterization of Isolated and Zwitterionic Forms of LTyrosine, Pharm. Anal. Acta, 2015, 6, 439.

54 C. D. Contreras, A. E. Ledesma, H. E. Lanus, J. Zinczuk and S. A. Brandan, Hydration of l-tyrosine in aqueous medium. An experimental and theoretical study by mixed quantum mechanical/molecular mechanics methods, Vib. Spectrosc., 2011, 57, 108-115.

55 Y. Wang, Y. Chang, Y. Li'ang, Y. Xue, Z. Li and C. Xue, A Novel Technological Process of Extracting L-Tyrosine with Low Fluorine Content from Defatted Antarctic Krill (Euphausia superba) By-product by Enzymatic Hydrolysis, Food Bioprocess Technol., 2015, 9, 621-627.

56 J. R. A. Moreno, M. del Mar Quesada Moreno, F. P. Ureña and J. J. L. González, Conformational preference of short aromatic amino acids from the FT-IR, FT-Raman and FarIR spectroscopies, and quantum chemical calculations: 1phenylalanine and l-tyrosine, Tetrahedron: Asymmetry, 2012, 23, 1084-1092.

57 A. Mostad, H. M. Nissen and C. Romming, Crystal structure of L-tyrosine, Acta Chem. Scand., 1972, 26, 3819-3833.

58 B. Sun, Z. Ji, Y. P. Liao, M. Wang, X. Wang, J. Dong, C. H. Chang, R. Li, H. Zhang, A. E. Nel and T. Xia, Engineering an effective immune adjuvant by designed control of shape and crystallinity of aluminum oxyhydroxide nanoparticles, ACS Nano, 2013, 7, 1083410849.

59 The Merck Index - Encyclopedia of Chemicals, Drugs and Biologicals ed. S. Budavari, Merck and Co, Rahway, NJ, US, 1989.

60 R. Carta, Solubilities of L-cystine, L-tyrosine, L-leucine, and glycine in sodium chloride solutions at various $\mathrm{pH}$ values, J. Chem. Thermodyn., 1998, 30, 379-387.

61 D. S. Leuthard, A. Duda, S. N. Freiberger, S. Weiss, I. Dommann, G. Fenini, E. Contassot, M. F. Kramer, M. A. Skinner, T. M. Kündig, M. D. Heath and P. Johansen, Microcrystalline Tyrosine and Aluminum as Adjuvants in Allergen-Specific Immunotherapy Protect from IgEMediated Reactivity in Mouse Models and Act Independently of Inflammasome and TLR Signaling, $J$. Immunol., 2018, 200, 3151-3159.

62 F. Liang, G. Lindgren, K. J. Sandgren, E. A. Thompson, J. R. Francica, A. Seubert, E. De Gregorio, S. Barnett, D. T. O'Hagan, N. J. Sullivan, R. A. Koup, R. A. Seder and $\mathrm{K}$. Loré, Vaccine priming is restricted to draining lymph nodes and controlled by adjuvant-mediated antigen uptake, Sci. Transl. Med., 2017, 9, eaal2094.

63 J. A. Champion, A. Walker and S. Mitragotri, Role of particle size in phagocytosis of polymeric microspheres, Pharm. Res., 2008, 25, 1815-1821.

64 Y. Tabata and Y. Ikada, Effect of the size and surface charge of polymer microspheres on their phagocytosis by macrophage, Biomaterials, 1988, 9, 356-362. 
65 M. K. Pratten and J. B. Lloyd, Pinocytosis and phagocytosis: the effect of size of a particulate substrate on its mode of capture by rat peritoneal macrophages cultured in vitro, Biochim. Biophys. Acta, 1986, 881, 307-313.

$66 \mathrm{~J}$. A. Champion and S. Mitragotri, Role of target geometry in phagocytosis, Proc. Natl. Acad. Sci. U. S. A., 2006, 103, 49304934.

67 D. Paul, S. Achouri, Y. Z. Yoon, J. Herre, C. E. Bryant and P. Cicuta, Phagocytosis Dynamics Depends on Target Shape, Biophys. J., 2013, 105, 1143-1150.

68 L. Delamarre, R. Couture, I. Mellman and E. S. Trombetta, Enhancing immunogenicity by limiting susceptibility to lysosomal proteolysis, J. Exp. Med., 2006, 203, 2049-2055.

69 B. Hansen, A. Sokolovska, H. HogenEsch and S. L. Hem, Relationship between the strength of antigen adsorption to an aluminum-containing adjuvant and the immune response, Vaccine, 2007, 25, 6618-6624.

70 B. Hansen, M. Belfast, G. Soung, L. Song, P. M. Egan, R. Capen, H. Hogenesch, R. Mancinelli and S. L. Hem, Effect of the strength of adsorption of hepatitis B surface antigen to aluminum hydroxide adjuvant on the immune response, Vaccine, 2009, 27, 888-892.
71 S. M. Noe, M. A. Green, H. HogenEsch and S. L. Hem, Mechanism of immunopotentiation by aluminumcontaining adjuvants elucidated by the relationship between antigen retention at the inoculation site and the immune response, Vaccine, 2010, 28, 3588-3594.

72 I. Berthold, M. L. Pombo, L. Wagner and J. L. Arciniega, Immunogenicity in mice of anthrax recombinant protective antigen in the presence of aluminum adjuvants, Vaccine, 2005, 23, 1993-1999.

73 I. Z. Romero Mendez, Y. Shi, H. HogenEsch and S. L. Hem, Potentiation of the immune response to non-adsorbed antigens by aluminum-containing adjuvants, Vaccine, 2007, 25, 825-833.

74 M. Lundqvist, J. Stigler, G. Elia, I. Lynch, T. Cedervall and K. A. Dawson, Nanoparticle size and surface properties determine the protein corona with possible implications for biological impacts, Proc. Natl. Acad. Sci. U. S. A., 2011, 105, 14265-14270.

75 P. Pacheco, D. White and T. Sulchek, Effects of microparticle size and Fc density on macrophage phagocytosis, PLoS One, 2013, 8, e60989. 